\title{
Comparison of Insecticide Effect of Plant Extracts on Aphids of Watermelon and Green Alfalfa
}

\author{
Abderrahmane Kassimi ${ }^{1} \&$ Lahcen El watik ${ }^{1}$ \\ ${ }^{1}$ Laboratory natural substances, Synthesis and molecular dynamics, Department of chemistry, Faculty of Science \\ and Technology of Errachidia, University My Ismail, Errachidia, Morocco \\ Correspondence: Abderrahmane Kassimi, Faculty of Science and Technology of Errachidia, University My Ismail, \\ Errachidia, Morocco. Tel: 212-666-915-777. E-mail: kass_abde97@yahoo.fr
}

Received: June 15, 2012 Accepted: July 20, 2012 Online Published: July 30, 2012

doi:10.5539/sar.v1n2p301

URL: http://dx.doi.org/10.5539/sar.v1n2p301

\begin{abstract}
The watermelon and the green alfalfa are important crops in Morocco. The ripe fruit of the watermelon has a high nutritional value, rich in vitamin and mineral salts and used for medicinal purposes (kidneys and cleaning of the urinary tract). The alfalfa green is principally cultivated for livestock feed.

A common problem in the production of watermelon and the alfalfa is the infestation by aphids. They transmit viruses of the tile to the plants. They are more likely to be a problem in the time costs. The study presents the effects of products Thyme, Oregano, Neem and their mixture on the aphids of watermelon in comparison with their effects on aphids of alfalfa green.

The tests were conducted of the months from May to September on the aphids on the fields of watermelon and alfalfa green. It determines the percentage of deaths of aphids in function of the dose $1 \%$ and $5 \%$ for these products and the time 3,5 and 7 hours after treatment. A comparison between the results obtained showed that the extract of Thyme is more active in watermelon and the Oregano is in alfalfa.
\end{abstract}

Keywords: watermelon, alfalfa, insecticide, aphid, neem, oregano, thyme

\section{Introduction}

The culture of the watermelon and alfalfa attract all the more the producers it generates substantial amount of income. Most importantly, it provides the gains to a period during which the situation that prevails at the level of a lot of farms require them to incur debts from other more affluent. It remains that the evolution observed in the culture there are a number of problems caused by the parasites and insecticides used. In the culture of green alfalfa, parasites such as the aphids cause especially of damage to the leaves, causing discoloration. They attack the young shoots and the buds. A severe attack led to the fall of the leaves. In Morocco, a few species of aphids have been found in large quantities on the alfalfa fields green.

Based on studies in Quebec, the parasitic diseases the most important leading the development of foliar spots among the alfalfa .The symptoms appear first on the basal leaves. The spots are circular (diameter $2 \mathrm{~mm}$ ), brown to dark brown, with an irregular margin (finely serrated). On the upper face of the spots, the fungus produces a fruiting which is in the form of a tiny point raised brown, located in the center of the stain. The affected leaves yellowing and fall (Lacroix, 2002).

Of the larva to adult, all stages feed on the underside of the leaves. They can affect the plant in different ways: reduction of photosynthesis, injection of phytotoxic substances while they are fed, accumulation of faeces and paintings on the plants that can affect the appearance of plants. All of these effects have consequences for the decrease of the usable quantity of plants and therefore causes great economic losses (Johnson \& Lyon, 1991).

The most important factors in the productivity of the watermelon are high temperatures, high humidity, exces rain, pests (aphids) and diseases (Žanic et al., 2009). Aphids have been one of the principal insect pests of watermelons in Louisiana, primarily because of their role in virus transmission. Melon aphid, green peach aphid, and cowpea aphid feed and reproduce on watermelons and other cucurbits. The other aphids listed are also involved in virus transmission (Harrison et al., 2002).

Damage from aphids can be direct or indirect. Direct damage to plants occurs from the feeding activity of aphid 
nymphs and adults. Aphids pierce the plant tissue and extract sap, which results in a variety of symptoms, including decreased growth rates and reduced vigor; mottling, yellowing, browning, or curling of leaves; and wilting, low yields, and plant death. Indirect damage is also caused by the ability of some aphid species to serve as virus vectors. The viruses transmitted by aphids can cause severe losses.Under favorable conditions, these viruses can cause a high rate of crop failure and severe economic losses (Barbercheck, 2011).

Even if pesticides have contributed to increase crop yields notably fighting against pests, the side effects of the use of pesticides are many: effects on the health of the people, the wildlife and flora; contamination of the water, soil and air. The World Health Organization advances the impressive figure of 3 million poisonings each year in the world due to pesticides with 220000 dead in total (Bouguerra, 1986).

Because these effects the man beging has sought alternative as the utilization of pesticides from oils.Horticultural oils can also be applied against aphids and aphid transmitted viruses. These oils are useful in interfering with the transmission of the viruses. They should be applied early in the growing season (two weeks after planting) as aphids are known to colonize plants shortly after germination (Katis et al., 2007). Neem and pyrethrin are other options, but care must be taken when using these broad- spectrum insecticides to prevent harm to beneficial insects (Liburd \& Nyoike, 2008).

Several plants provide natural insecticides, but their extent and their specific action often have led us to focus our research on the Neem, Oregano and Thyme. These plants are also used for many uses. The growing interest in the use of pesticides based on extracts from these plants in the world is motivated by their effects comparable to those of chemical pesticides (Mouffok et al., 2007/2008).

This work has for objective to make a comparison of insecticide effect of Neem Products, Oregano, Thyme and their mixture on aphids of watermelon and green alfalfa in order to reduce the damage caused by these parasites in protecting the environment and in assessing the effect of insecticide natural products used in this study.

\section{Methods and Materials}

\subsection{Culture}

\subsubsection{Green Alfalfa}

Alfalfa (Lucerne) is the common name, Medicago sativa (Latin name) and Fabaceae/Leguminosae (Pea family) is the family name. Its scientific name: Medicago is neighbor of the Latin designation: Medica (Virgil and Pliny). This name is derived from the Greek: Medike which designated the origin of this plant, introduced of the Medes after the expedition of Darius, cited by Theophrastos in his book: Research on the plants (Coutin, 2001).

Alfalfa has many environmental benefits as the subtraction of inorganic nitrogen in the process of leaching, the treatment of effluents rich in nitrogen and the positive impact on biodiversity. It is also a strategic stake in economic independence and protein for the feeding (Thiebeau et al., 2003).

\subsubsection{Watermelon}

Watermelon is the common name, Latin name is Citrullus lanatus (Thunberg) Matsumara \& Nakai (also called $C$. vulgaris) and Cucurbitaceae is the family name (Rhodes, 2008). Fruits with seeds which the arrangement of the plants is $2 \mathrm{~m} \times 1 \mathrm{~m}$ between hills. Its varieties are Sugar Belle and Royal Jubilee and its duration of culture is from 70 to 95 days. The potential return in high productivity gives the fruit of 5 to $12 \mathrm{~kg}$. The watermelon prefers warmer temperatures and a long growing season.

Medicago sativa and Citrullus lanatus are the major present cultures in our region and the most answered in Morocco in summer.They give a great economic return for the farmers.

\subsection{Substances Used as Natural Insecticides}

Reagents used in this work have been provided by Herb' Atlas, supplier of natural products, organic and conventional essential oils.

\subsubsection{Neem Vegetable Oil (VO)}

The botanical name of Neem, also known as Indian Lilac, is Azadirachta indica. Neem is an evergreen tree native to India, Burma, Java and the Lesser Sunda Islands (Mouffok et al., 2007/2008). Neem oil is obtained by cold pressing and sand filtration. The active mole-cule is azadirachtin $(0.29 \%)$.

\subsubsection{Thyme Essential Oil (EO)}

The species used in this work is Thymus satureoïdes (Moroccan red Thyme), an endemic plant found in forest clearings, scrub and matorrals of low and medium mountains. The thyme essential oil is obtained by 
hydro-distillation by steam distillation. The major components of the oil are alpha-terpineol + borneol $(39.23 \%)$, camphene $(9.25 \%)$, carvacrol $(7.93 \%)$ and terpinen-4-ol + beta-caryophyllene $(7.06 \%)$.

\subsubsection{Oregano Essential Oil (EO)}

The oregano used, Origanum compactum, is widely available in the North of Morocco. The method used for obtaining the essential oil of Oregano is hydro-distillation by steam distillation. Its major constituents are carvacrol $(32.14 \%)$, thymol $(21.42 \%)$ and y-terpinene (18.80\%).

\subsubsection{Mixture}

The mixture was obtained from the products and equal in percentage volumes of Thyme, Oregano and Neem in all experiments.

\subsection{Description and Characterisation of the Aphids}

The Latin name are Adelgides, Aphidides, Eriosomatides, Phylloxerides and the Common name is Aphids.Aphids belong to the insects, more precisely to the Homoptera order and Aphididae family. They are polyphagous, sucking biting insects. Aphids are usually soft body, pear-shaped. A single morphological character distinguishes them from other insects is the presence of cornicles. They were identified with a magnifying glass of $8 \mathrm{x}$ and they present the following characteristics: $0.25 \mathrm{~mm}-2.5 \mathrm{~mm}$ long, dark and light green head, dark and light green chest, yellow-green and light green abdomen.

\subsubsection{Aphids of Alfalfa}

There are the alfalfa aphid (Macrosiphum creelii), blue alfalfa aphid (Acyrthosiphon kondoi), green peach aphid (Myzus persicae), pea aphid (Acyrthosiphon pisum) and spotted alfalfa aphid (Therioaphis maculata) (Knowles, 1998).

\subsubsection{Aphids of Watermelon}

There are the aphids of the cotton aphid (melon), Aphis gossypii Glover on all cucurbits. It is an aphid-green blackish, about 1 to $2 \mathrm{~mm}$ long. The siphunculi and the cauda (the tail) are black in color. There are also the aphids green of the fish, Myzus than (Sulz). It is a vector of cucumber mosaic and other viruses that can attack the cucurbits. To combat these aphids we used a spray of extracts of Neem, spraying of extracts of tobacco or use of ashes of wood (Bijlmakers \& Verhoek, 1995).

\subsection{Experimental Conditions and Method}

\subsubsection{Conditions}

The tests have been realized in the months of May to September in watermelon fields. The other tests have been done from early May to late September in alfalfa green fields. The geographical area chosen is near the town of Erfoud; Ziz Oasis named Tafilalt southeast Morocco. The area of fields ranged from 0.1 to 0.5 hectare. In order to carry out these experiments random plots of $1 \mathrm{~m}^{2}$ were taken, mutually separated by $10 \mathrm{~m}$ for sufficient insulation.

\subsubsection{Experiments and Procedures}

The experiments consist of evaluating the mortality on aphids in the presence of dilute solutions of oils using a methodology inspired by the protocol of the World Health Organization (WHO, 1985). In that way, previous experiments allowed selecting a range of concentrations for the tests. According to this, stock solutions of each oil sample were prepared in pure water. From these solutions we have made the final dilutions at different concentration percentages ( $\mathrm{v} / \mathrm{v})(1 \%$ and $5 \%$ oil in pure water).

Each plot was sprayed with $100 \mathrm{ml}$ of a solution (oil + water $+1 \mathrm{ml}$ of liquid soap per liter of solution as an emulsifier) by use of a manual sprayer. Aphids parasitizing fields of $1 \mathrm{~m}^{2}$ surface were taken immediately after treatment in $25 \times 40 \mathrm{~cm}^{2}$ clear plastic bags for later counting in the laboratory. In order to verify the reproducibility of the results each test was repeated four times.

A control sample (test non-treaty by the oil) of $100 \mathrm{ml}$ of pure water and emulsifier enables to measure the natural mortality at the same experimental conditions as the other tested. The count of dead aphids on the last 20 $\mathrm{cm}$ of plants taken in a $1 \mathrm{~m}^{2}$ surface area has been accomplished by means of a magnifying glass $8 \mathrm{x}$ at 3,5 and 7 hours after treatment. The same procedure was conducted for the other plots in concentrations ( $1 \%$ and $5 \%)$.

\section{Results}

The application of the studied oils on the aphids at different concentrations causes mortality during the first hours after treatment as shown in table 1 . Each mortality percentage $(\mathrm{m} \pm$ SEM where $\mathrm{m}$ is average mortality for 
number of repetition on a test and SEM is the Standard Error of Measurement) presented in Table 1 is the average of four tests (four under test to a test) which have the unavoidable uncertainty of the measurement.

Table 1. Aphid mortality percentage in terms of time after exposure and oil solution concentration (The values in italics are those of the watermelon and the others are of the green alfalfa)

\begin{tabular}{|c|c|c|c|c|c|c|}
\hline \multirow{2}{*}{$\begin{array}{l}\text { Concentration } \\
(\mathrm{v} / \mathrm{v})\end{array}$} & \multicolumn{6}{|c|}{ Mortality in percentage $(\%)$} \\
\hline & Time (h) & VO Neem & EO Thyme & EO Oregano & Mixture & Control \\
\hline \multirow{6}{*}{$1 \%$} & \multirow{2}{*}{3} & $36.94 \pm 0.81$ & $40.64 \pm 0.93$ & $44.38 \pm 0.62$ & $45.82 \pm 0.62$ & $4.68 \pm 1.51$ \\
\hline & & $23.47 \pm 1.25$ & $37.34 \pm 2.49$ & $30.1 \pm 3.12$ & $34.42 \pm 3.24$ & $1.22 \pm 0.12$ \\
\hline & \multirow{2}{*}{5} & $75.2 \pm 0.54$ & $71.97 \pm 1.02$ & $80.09 \pm 0.93$ & $72.91 \pm 0.55$ & $7.4 \pm 1.35$ \\
\hline & & $32.3 \pm 1.46$ & $41 \pm 1.78$ & $34.66 \pm 3.34$ & $43.4 \pm 2.82$ & $1.83 \pm 0.26$ \\
\hline & \multirow{2}{*}{7} & $88.26 \pm 0.92$ & $86.29 \pm 0.92$ & $93.7 \pm 1.2$ & $85.66 \pm 0.45$ & $10.13 \pm 1.2$ \\
\hline & & $36.01 \pm 1.5$ & $43.47 \pm 2.04$ & $37.75 \pm 2.66$ & $46.06 \pm 2.85$ & $2.13 \pm 0.3$ \\
\hline \multirow{6}{*}{$5 \%$} & \multirow{2}{*}{3} & $44.98 \pm 0.63$ & $45.33 \pm 0.78$ & $54.43 \pm 0.8$ & $50 \pm 0.54$ & $4.8 \pm 0.41$ \\
\hline & & $36.88 \pm 1.18$ & $55.3 \pm 4.13$ & $46.22 \pm 2.56$ & $34.64 \pm 3.38$ & $1.2 \pm 0.22$ \\
\hline & \multirow{2}{*}{5} & $76.53 \pm 0.99$ & $75.39 \pm 1.18$ & $79.74 \pm 0.89$ & $75.48 \pm 0.7$ & $5.84 \pm 0.63$ \\
\hline & & $43.85 \pm 2.4$ & $63.24 \pm 5.27$ & $51.34 \pm 3.2$ & $40.88 \pm 2.21$ & $1.8 \pm 0.34$ \\
\hline & \multirow{2}{*}{7} & $90.83 \pm 1.16$ & $89.23 \pm 1.68$ & $92.17 \pm 1.23$ & $89.95 \pm 0.85$ & $6.89 \pm 0.85$ \\
\hline & & $45.98 \pm 2.68$ & $65.89 \pm 4.97$ & $52.48 \pm 3.27$ & $44.27 \pm 2.69$ & $2.1 \pm 0.39$ \\
\hline
\end{tabular}

The Table 1 shows that after hours of experience the witness did not exceed $10.13 \%$ mortality in all tests. We see that by the dose $1 \%$ or $5 \%$ mortality is low in watermelon. These mortality rates are almost stabilized at the end of each test, which proves that the effect of the products is fast compared with that of other extracts such as Melia volkensii or the effect is observed on two weeks (Diop \& Wilps, 1997).

After three hours of treatment, for each product employee the mortality rate increases as a function of the concentration but does not exceed in watermelon $37.34 \%$ of the Thyme and alfalfa $45.82 \%$ of the mixture at low concentration. But to the dose $5 \%$ the mortality rate in watermelon is $55.3 \%$ of the Thyme and alfalfa $54.43 \%$ of the Oregano. In addition, the essential oil of Thyme seems to be active for the watermelon.

After seven hours of treatment the variation of the mortality rate of aphids in function of the concentration evolved weakly by comparing with the previous case (three hours). The mortality for the dose $5 \%$ in watermelon is $65.89 \%$ of the Thyme and alfalfa was $92.17 \%$ of the Oregano. But for the dose $1 \%$ mortality in watermelon is $43.47 \%$ of the Thyme and alfalfa $93.7 \%$ of the Oregano. The Thyme remains active in watermelon but the Oregano which is active in alfalfa.

From these results, the essential oil of Thyme and the mixture seem to be the most active in first hour. Also the Thyme remains active at a high dose in watermelon but the mixture is not in alfalfa or Oregano is active. It is observed that the mortality varies little even at a high dose. It is likely to remain far from the great values of mortalities in watermelon.

To evaluate more precisely the insecticide activity of these products against aphids, it was calculated the $\mathrm{TL}_{50}$ and the $\mathrm{TL}_{90}$, defined as the time lethal causing $50 \%$ and $90 \%$ of mortality in the population of aphids treated. These values were determined from an experimental curve giving the variations of the percentage of mortality to $1 \%$ and $5 \%$ depending on the increasing time in the Table 2 . In addition we calculated the $\mathrm{CL}_{50}$ and $\mathrm{CL}_{90}$ as the lethal concentrations causing $50 \%$ and $90 \%$ of mortality in the population of aphids treated in Table 2 . 
Table 2. $\mathrm{TL}_{50}$ and $\mathrm{TL}_{90}$ for $1 \%$ and $5 \%$ product concentration; $\mathrm{LC}_{50}$ and $\mathrm{LC}_{90}$ for 7 hours after treatment (The values in italics are those of the watermelon and the others are of the green alfalfa)

\begin{tabular}{lllllllllllll}
\hline & \multicolumn{4}{c}{$\mathrm{TL}_{50}$} & \multicolumn{4}{c}{$\mathrm{TL}_{90}$} & \multicolumn{2}{c}{$\mathrm{LC}_{50}$} & \multicolumn{2}{c}{$\mathrm{LC}_{90}$} \\
\cline { 2 - 13 } & $1 \%$ & \multicolumn{3}{c}{$5 \%$} & $1 \%$ & & $5 \%$ & & After 7 hours & After 7 hours \\
\hline Neem & $4 \mathrm{~h}$ & $12.25 \mathrm{~h}$ & $3.5 \mathrm{~h}$ & $9 \mathrm{~h}$ & $6.8 \mathrm{~h}$ & $24.5 \mathrm{~h}$ & $6.8 \mathrm{~h}$ & $20.25 \mathrm{~h}$ & $1.25 \%$ & $5.25 \%$ & $5 \%$ & $11.5 \%$ \\
Thyme & $4.75 \mathrm{~h}$ & $9.75 \mathrm{~h}$ & $3.5 \mathrm{~h}$ & $6.5 \mathrm{~h}$ & $7.25 \mathrm{~h}$ & $20.75 \mathrm{~h}$ & $7 \mathrm{~h}$ & $13 \mathrm{~h}$ & $1.5 \%$ & $4 \%$ & $8.5 \%$ & $7 \%$ \\
Oregano & $3.5 \mathrm{~h}$ & $11.75 \mathrm{~h}$ & 2.75 & $7 \mathrm{~h}$ & $6.5 \mathrm{~h}$ & $24 \mathrm{~h}$ & $6.75 \mathrm{~h}$ & $18.25 \mathrm{~h}$ & $0.5 \%$ & $4.25 \%$ & $1 \%$ & $9.5 \%$ \\
Mixture & $3.5 \mathrm{~h}$ & $9 \mathrm{~h}$ & $3 \mathrm{~h}$ & $9.5 \mathrm{~h}$ & $7.25 \mathrm{~h}$ & $19 \mathrm{~h}$ & $7 \mathrm{~h}$ & $21 \mathrm{~h}$ & $1.5 \%$ & $5.5 \%$ & $5.25 \%$ & $13.5 \%$ \\
\hline
\end{tabular}

\subsection{Lethal Concentration Causing $50 \%$ and $90 \%$ of Mortality ( $L C_{50}$ and $\left.L C_{90}\right)$}

After seven hours of the treatment they reached a $50 \%$ mortality of aphids in watermelon to low dose $4 \%$ of Thyme and alfalfa for $0.5 \%$ of the Oregano. It was the mortality of $50 \%$ of the aphid after seven hours of treatment from the concentrations close to $5 \%$ of the products in watermelon. We reached a $90 \%$ mortality of aphids after seven hours of the treatment from the low dose $7 \%$ of Thyme in watermelon and alfalfa for $1 \%$ of the Oregano. Then the Thyme is more active in alfalfa and the Oregano is one of the most active in watermelon.

\subsection{Lethal Time Causing $50 \%$ and $90 \%$ of Mortality ( $T L_{50}$ and $\left.T L_{90}\right)$}

The mortality of aphids reached $50 \%$ for the dose $1 \%$ of the mixture from 9 hours in watermelon and products Oregano more the mixture from 3.5 hours .But for the dose $5 \%$ of the Thyme from 6.5 hours in watermelon and the Oregano more Neem from 3.5 hours. For the dose $1 \%$ we have that the mixture gives a mortality rate of over $90 \%$ from 19 hours in watermelon and the Oregano from 6.5 hours in alfalfa. At a dose of 5\% was this mortality in watermelon for the product Thyme from 13 hours and in alfalfa for the product Oregano from 6.75 hours.

It can be inferred that the product of Thyme is the most deadly of aphids in the fields of watermelon and the Oregano is the most deadly of aphids in alfalfa fields. More than 24 hours after treatment to achieve mortality rate of $90 \%$ in watermelon and 7 hours in alfalfa. This shows that all products even at low concentrations are already active after dozens of hours.

After treatment, the mortality is quick, with the high dose and reached $65 \%$ in watermelon and $92 \%$ in alfalfa but remains less rapid for the low dose by contribution to the witness. The comments after hour show a very low activity of aphids treated with the dose $5 \%$ which implies that the concentrated action of the oil on the ground can increase the rate of mortality. However, the death of aphids is preceded by a paralysis of the first hours. To the witnesses the vegetation has not been renewed among aphids that had continued to consume their food.

\section{Discussion}

It can be assumed that the mortality is mainly due to the various active compounds containing in these products, the dose used and the processing time of aphids. The increase in dose makes the oil very active against aphids; this can lead to dilution and a modification of the metabolism. This is demonstrated by the assumption of Isman (Isman, 1999) or the essential oils act directly on the cuticle of insects and mites to soft body because they appear to be more effective on the arthropods to soft body as the case of the Facin who exercised a suppression satisfactory on thrips, aphids, the a whitefly and some mites.

Butler and Henneberry (Butler \& Henneberry, 1990) have tested a solution of 5 to $10 \%$ of the oil from the seeds of cotton on the aphids of the cabbage, the couple, the thrips and the to legionnaire in the beet. The oil from the seeds of cotton has reduced up to $91 \%$ the number of larval legionaries on the bette to carde. The spotted have been significantly reduced for 7 days on the celery with a solution to $5 \%$. The populations of aphids were $86 \%$ less on the seedlings of cabbages rosettes on the treaties that witnesses 16 days after the treatment.

In relation to the witness, it is the treatment of aphids by the Thyme in watermelon and the Oregano in alfalfa which are found the most affected. These two cases in which the concentrations were sufficient to cause the death which has engendered of disturbances in the behavior of the insect. The oils of Oregano, Basil, de Marjoram, Thyme, Sage, Laurier, Rosemary, Lavender, Anise, Mint, Celery, Cumin, Citrus Fruit, Coriander and de Fennel have been tested and several have caused up to $100 \%$ of mortality in the small borer of cereals, Rhysopertha dominica (F.), the saw-toothed grain beetle, Oryzaephilus surinamensis (L.), the red flour beetle, Tribolium castaneum (Hbst.) and the rice weevil (Shaaya et al., 1991). 


\section{Conclusion}

The results of our study have allowed to say that the dose $1 \%$ of the products applied on aphids does not have much of an impact, this may be due to two reasons: the dose is insufficient and/or these pests are more resistant. For the dose $5 \%$, all samples showed an interesting activity on aphids. With time, the extracts of Thyme in watermelon and the Oregano in alfalfa green being the samples the most effective and reaches a mortality rate more than $65 \%$ for the high dose.

A low dose mixing oils seems the more active, but is not at a high dose. You can have a complexation between the different compounds which gave a decrease of the insecticide activity. This will allow observing the different changes on the qualitative and quantitative terms of the essential oils in order to estimate to what conditions or at what period and to what culture such or such essential oil could give a satisfactory performance or have an interesting activity.

In effect, the natural extracts of plants are a true wealth and can be the cause of a large number of substances insecticides exploitable in the control of pests (Isman, 2001). In this context, the use of natural molecules of interest (ecological and economic) to the insecticidal properties of lesser toxicity in man is proving to be an alternative approach to the use of insecticides of synthesis.

\section{References}

Barbercheck, M. (2011). Biology and Management of Aphids in Organic Production Systems.eOrganic article.

Bijlmakers, H. W. L., \& Verhoek, B. A. (1995). Cultures vivrières et maraîchères. Guide de Défense des Cultures auTchad .Rome. p. 73.

Bouguerra, M. L. (1986). Les pesticides et le tiers monde. La Recherche, ${ }^{\circ} 176$.

Butler, G. D. Jr., \& Henneberry, T. J. (1990). Cottonseed oil and safer soap: effects on cotton and vegetable pests and phytotoxicity. The Southwestern Entomologist, 15(3),257-264.

Coutin, R. (2001). Principaux invertébrés de la Luzerne Cultivée. Insectes 19 nº 122 (3).

Diop, B., \& Wilps, H. (1997). Field trials with neemoil and Melia volkensii on Schistocerca gregaria. In New strategies in locust control. S. Krall, R. Pevelling et D. Ba Diallo éditeurs. Birkhäuser Verlag. Basel/ Switzerland. http://dx.doi.org/10.1007/978-3-0348-9202-5_26

Harrison, H., Boudreaux, J., Motsenbocker, C., \& Beckley, P. (2002) .Crop Profile for Watermelon in Louisiana.

Herb'Atlas plantes Aromatiques, Médicinales et huiles essentielles 171, Rue de Crimée 13003 Marseille-France, www.bio-essentiel.com-www.herbatlas.com

Isman, M. (1999). Pesticides based on plant essential oils. Pesticide Outlook, April 1999, 68-72.

Isman, M. B. (2001). Pesticides based on plant essential oils for management of plant pests and diseases. In: International symposium on development of natural pesticides from forest resources. Korea Forest Reasearch Institute, Seoul, Korea. pp. 1-9.

Johnson, W. T., \& Lyon, H. H. (1991). Insects That Feed on Trees and Shrubs (2nd). Comstock Publishing/Cornell University Press, Ithaca. pp. 468-470.

Katis, N. I., Tsitsipis, J. A., Stevens, M., \& Powell, G. (2007). Transmission of plant viruses In H. van Emden and R. Harrington [eds.]. Aphids as crop pests CAB International, Wallingford, UK.

Knowles, T. C. (1998). Alfalfa Aphid Complex (Blue Alfalfa Aphid, Pea Aphid, and the Spotted Alfalfa Aphid). College of Agriculture and Life Sciences, University of Arizona.

Lacroix, M. (2002). Maladies des Cereales et de la luzerne, Laboratoire de diagnostic en phytoprotection, Direction de l'innovation scientifique et technologique. p. 18.

Liburd, O. E., \& Nyoike, T. W. (2008). Biology and Management of Aphids in Sustainable Field Production of Cucurbits. ENY-847 (IN761), one of a series of the Entomology \& Nematology Department, Florida Cooperative Extension Service, Institute of Food and Agricultural Sciences, University of Florida, p. 3.

Mouffok, B., Raffy, E., Urruty, N., \& Zicola, J. (2007/2008). Département : Génie Biologique Projet tutoré du S2 (cursus).

Mouffok, B., Raffy, E., Urruty, N., \& Zicola J. (2007/2008). Le neem, un insecticide biologique efficace. (Projet tutoré du S2) Université Paul Sabatier, Auch. p. 14.

Rhodes, D. (2008). Watermelon-Notes. Vegetable Crops-HORT410. Department of Horticulture \& Landscape 
Architecture.

Shaaya, E., Ravid, U., Paster, N., Juven, B., Zisman, U., \& Pissarev, V. (1991). Fumigant toxicity of essential oils against four major stored-product insects. J. Chem. Ecol, 17(3), 499-504. http://dx.doi.org/10.1007/BF00982120

Thiebeau, P., Parnaudeau, V., \& Guy, P. (2003). Quel avenir pour la luzerne en France et en Europe ? Courrier de l'environnement de l'INRA, 49, 29-46.

World Health Organization (WHO). (1985). Bioassay method for the titration of Bacillus sphaericus: consultation on the development of Bacillus sphaer-icus as a microbial larvicide. World Health Organ, 3, $85-95$.

Žanic, K., Ban, D., Škaljac, M., Dumicic, G., Ban, S. G., \& Žnidarcic, D. (2009). Aphid population in watermelon (Citrullus lanatus Thunb) production. Acta agriculturae Slovenica, 93-2, p. 192. 